\title{
"Blended Conference" as Video Supported Event Format in the Educational Marketing Mix of Sports Organizations
}

\author{
By Rebecca Gebler-Branch ${ }^{*}$
}

\begin{abstract}
The question whether the "event" is an effective marketing tool or not has been extensively discussed and demonstrated in recent years. In particular in the case of brand messages, the event has become absolutely indispensable in the tool mix. Also in the field of educational marketing, the messages must also be brought to life. As a partner for sports organizations in the digital education sector we accompany our clients in the introduction and implementation of new formats in education and training. This also includes support in the process of making known the plan primarily within the organization itself, for example an association. In this connection over the past years we have worked intensively on the development of strategies and marketing tools which assist our clients to bring alive the message of the new approach to education. In this article the innovative event format "Blended Conference" is presented by means of a real example and discussed in relation to its development potential in sports sector educational marketing. The format is based on the concept structure of Blended Learning as known in the education sector. By enlarging the physical event space with a virtual one, many new possibilities open up on a variety of levels of multi-sensual perception by the recipients. The event, which comprises online and presence times, can be placed in the category of "hybrid events". The combination of online, presence and online wrap phase, places great focus on the continuous involvement of the recipient. This gives rise to three central dimensions served by this format: Information, interaction and inspiration. In each phase the focus lies on another dimension. Thanks to this blended approach, those taking part at the event, can experience the staged message in various and intense ways.
\end{abstract}

Keywords: Blended Conference, Conference Format, Education Marketing, Sport, Social Collaboration

\section{Introduction}

Since 2000 the EU-Commission campaigns in its memorandum for the concept of "livelong learning" in order to improve living conditions within a society of knowledge (Kommission 2000). The idea of "lifelong learning" contains for instance new basic qualifications for active citizens who want to participate in a knowledge society, higher investments in human resources, innovative learning and teaching methods, new assessment concepts in education and the acknowledgement of informal education processes (Schüller-Zwierlein and Stang, 2011). For considerable time, society has recognized that education and learning take place not only in classical education establishments such as schools, universities or further education and training institutes. If I want to learn,

*Head Marketing and Sales, Ghostthinker Gmbh, Germany. 
nowadays I have a variety of offers and providers to choose from. The spectrum of free possibilities, for example, YouTube or (private) Blogs, through to fee-based programs (online) universities or further training institutes. Marketing of such offers is known as education marketing (Bernecker 2007).

Many agencies and marketing managers in the education sector today rely on events as a central measure in the classic marketing mix in order to communicate their message to the target group. "Events take their special quality of communication from multi-sensuality, i.e. experiencing with all the senses and from personal, face-to-face contact of those attending the event with the companies who organized it" (Zanger 2013, according to Zanger and Sistenich 1996, Zanger 2001, 2010).

The high level effectiveness of this instrument, in particular "experiencing" the message, has been looked into over recent years and is here not the subject for discussion.

This article deals with (a) how the classic concept, i.e. presence-based event format in an educational context, can be extended through media-supported forms of communication and collaboration (conception), (b) what form could the implementation of such an event in a sport organization take for the provider of the education (implementation) and (c) how do those taking part and the organizers assess the results (evaluation). Following this introduction, in section 2 I outline the context "German Sports Organization" with focus on the theme of education marketing, before then in section 3, compiling the fundamental concept principles for a "Blended Conference" as a new event format. Section 4 gives insight into the implementation of the Blended Conference in the case of the German Rugby Association and the first German Rugby Forum 2018. Section 5 summarizes the most important evaluation results. The article ends with a summarized conclusion.

\section{Education Marketing in German Sport}

Organized sport makes a substantial contribution to the general feeling of wellbeing in Germany in that "sport clubs allow the local people to have a part in society as well as making a great contribution to education, health, social integration and inclusion in and through sport (DOSB 2018). Through its qualification system and the granting of licenses the German Olympic Sport Association as the umbrella organization for organized sports ensures, for example, those trainers (coaches) are enabled to gain the competences to teach sports with the needed expertise and oriented to the respective target group. In order to receive such a license, interested parties must be appropriately qualified and provide proof of further educational training (DOSB 2013).

This process is supervised by the German Olympic Sport Association as the umbrella organization for all its 101 member associations and the reason why it is considered as one of the major education providers in Germany. Together these organizations educate approximately 45,000 men and women as coaches, youth leaders and club managers etc. (DOSB 2013). In these professional training courses it is not always just about pure theory but also themes beyond this, such as 
building up method and social competence. The spectrum of offers provided by these organizations is huge and diverse. Nevertheless, as the DOSB report 2013 "Das habe ich im Sport gelernt" shows, many of these organizations, especially the smaller ones are facing different challenges. Due to the lack of people who are working as instructors, it is not always possible to offer a licensing program that pleases the potential target group especially in rural regions. There are a few reasons for this: In the case of the target group "future coaches" outlined here, these are for the most part voluntary workers, in other words, not only do they give up their free time but are also expected to take part in further training courses. It often is the case that these persons have to take a vacation from work in order to take part in training courses, which sometimes take several weeks. This applies not only to the people who want to become a coach (or participate in a further training) but also to the teachers themselves. Depending on the size and strength of the association, it is possible that those responsible for the educational program are also often working on a voluntary base. The result is a decreasing amount of registered coaches with an official DOSB license (DOSB 2013).

One of the causes certainly lies in the development of society over the last years. Whereas up to the middle of the last century, commitment on a voluntary basis was part and parcel of urban and rural life, today it is very difficult to get people, especially younger people, interested in an honorary office (Braun 2014). Sport organizations today are in competition with many other leisure time opportunities for their members. Presumably it is then also difficult to win people over, to undertake further training courses in their free time. The study "Freiwilliges Engagement in Deutschland" done in 2014 shows, that voluntary commitment still plays an important role in German society, however it increases very slowly (Simonson, Vogel, Tesch-Römer 2014). Knowing this trend, the DOSB department for education points out, that sport organizations have to be aware that the motivation to become a coach has shifted. To be just active on a voluntary base sometimes is no longer enough. They emphasize, that sports organizations should promote as well their staff environment, their teams and the possibilities to grow personally by using the advantage that comes along with the various education programs. This applies to the education programs for future coaches as well to those who want or have to take part in a further training (Netzathleten 2017).

These explanations show that the mind-set in terms of coaches' education needs to be shifted from "just a non-arguable part" of being a coach towards a "beneficial and valuable chance" through which one can develop various and recognized competences. Therefore it is important for sports organizations to give more consideration to the state of the art of tools and methods in education in order to be able to offer programs that develop various competences (see 1. Introduction the concept of lifelong learning). In addition to this however, education departments in sports organizations have to incorporate adequate marketing activities as an inherent component of their work in order to be able to promote their programs effectively and to support the mental shift.

We have been partnering with sports organizations in the field of digital education for many years. During this period we have been witnessing the various 
challenges many of them are facing on their journey to implement a new education format in their organization. This motivated us to create an advertising format with which firstly optimum use of the limited resources of the organizations can be attained and secondly, to reach the target group with the appropriate effectiveness. From this arose the three following objectives: to create state of the art marketing instruments which reach the target group, make the new education approach come alive and this at the same time with manageable financial and personnel costs.

One marketing tool which meets these requirements and which is extremely compatible with the sports sector is the instrument "Event".

\section{"Blended Conference": Conception Principles from the Marketing Viewpoint}

How we spend our free and leisure time generally depends on our interests as well as the amount of time that we have available. As most members of the target group "potential coaches" are carrying out their commitment towards their sports organization in their leisure time, the educational programs have to fit two components: interest and time invest. In other words, educational programs in sports at least on a voluntary base have to compete with fun activities. Therefore, in order to be sure of gaining the attention of the desired target group, the department for education in each organization that offers educational programs must take appropriately convincing measures to make the offers visible.

Research in the field of marketing has shown that the "Event" is of major significance in the mix of marketing tools (Zanger 1996, 2007). Due to its special orchestration of messages, the visitor to a marketing event can be immersed in the brand world, experience it fully and be able to escape from everyday life (Drengner 2007, Schäfer -Mehdi 2009). The objectives of a marketing event therefore include the creation of a new reality for all those taking part.

The brand world created at events differs mostly from all-embracing social reality, the daily reality and daily experience as described by Berger and Luckmann in their treatise "Society's Construction of Reality" (Berger and Luckmann 1969). It is the possibility of escape from reality in which everything is regulated and with predetermined values, which fascinates people at events. Moreover, the concept is interactive and promotes dialogue. An event plans various roles for its visitors. Erving Goffman examined how these are designed, justified and developed in his treatise "We all put on an act" from the year 1959. The role is always connected with expectations and duties, where dialogue and progress arise and which can lead to this new reality becoming reality.

Zanger (2007) defined the following features, which characterize a marketing event:

- Multi-sensual address to those taking part at the event

- Intensive activation of those addressed with emotional anchoring of the message

- Creation of brand worlds and events actually experienced (brands)

- Long-lasting influence on public attitude 
- Creation of brand worlds as a change from daily life, but emotions experienced there are taken over by the recipient back in daily life.

- Marketing events are designed as very oriented to target group such that the individuality demands of the recipient are fulfilled, thus increasing contact intensity between customer and potential buyer.

The main objective of a marketing event is to convey a message specifically of the respective brand/organization/company and to anchor it with the recipient. The multi-sensual, interactive and dialogue-based direct address to the visitor enables this transporting or experiencing of messages, ideas or brands at a different level.

In the conception of our new event format we have concentrated on the features which characterize the event and have translated these into the requirements of (sport) education marketing. This is elementary as in the field of education marketing and our special context, it is all about the spreading of the message that further education in the sport sector is innovative and valuable.

Blended Conference makes use of the organizational structure (Illustration 1) known in the education sector as Blended Learning, with alternating online and presence phases as already postulated also in the sports sector since 2009 (Vohle 2009). Blended Learning is defined as "learning with various media and methods with the incorporation of virtual and physical arenas" (Reinmann 2011).

The extension of the physical event by means of interaction in the digital arena puts Blended Conference in the category of "hybrid events" (Zanger 2013).

Our concept of the Blended Conference as a rule provides three event phases: An introductory online phase in an online environment, the physical meeting at the location and a wrap-up online phase also in the online environment. These phases can be repeated practically as often as wished although in this case the challenge of maintaining the suspense curve will not be easier.

\section{Illustration 1. Structure of Blended Conference}

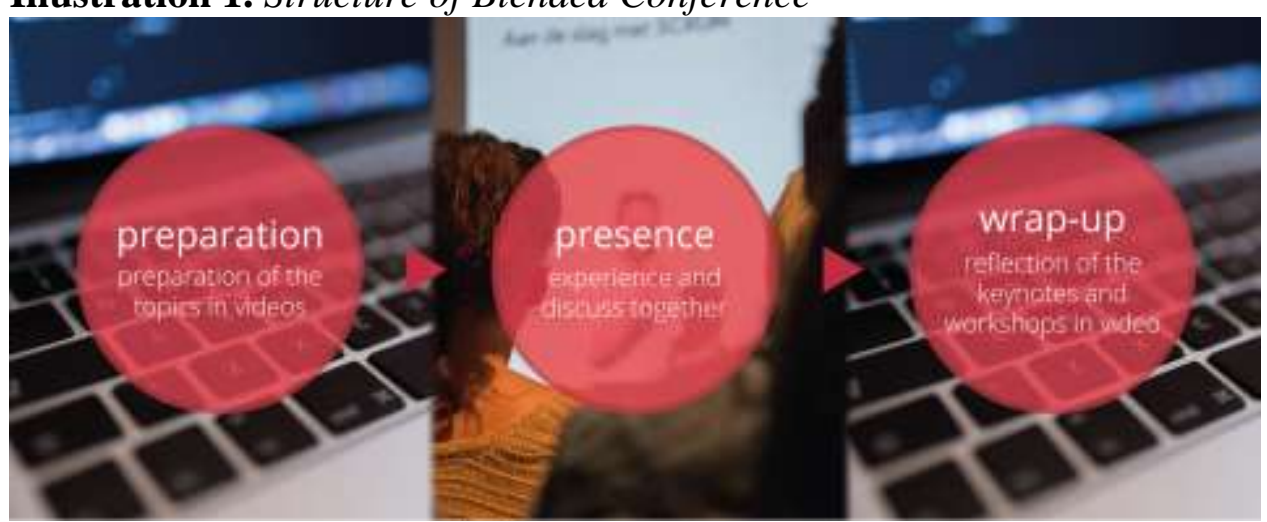

Source: Ghostthinker GmbH 2018.

The event is therefore structured in the same way as a training course-unit in the Blended Learning format. Exactly the format that many education managers in their associations would like to introduce under the framework, for example, of a new organization of coaches training and which must also be advertised. Whereas 
the idea of "blended" and digital media in the context of education may for some people give rise to uncertainty and sometimes even fear that one does not know how to use these media, the use of digital media in the context of events is, although still regarded as new, seen as interesting and fully accepted. Under the framework of a Blended Conference the participants enjoy the experience in a quite natural way and without a direct focus on "education" which is what a mixture of online and presence means. If one considers that many education departments are facing the challenge of convincing not only their members but also the functionaries of the association of the necessity for digital media, then it soon becomes clear just how suitable this format is in order to make the message of the education managers come to life.

Each of the three phases makes its specific contribution to information, interaction and inspiration amongst participants. These are also the three central dimensions, which serve this innovative event format. In the introductory phase the focus is firstly on information for the participants in respect of the theme of the event. In this way all those involved (students and teachers) are able to experience a more intensive and most of all, a more interactive program on the day of the personal meeting. The format allows the individual event contents (presentations, workshops etc.) to be recorded on video and entered in the online environment. Those taking part in the Blended Conference then have the opportunity in the wrap-up online phase to review the event or even to look in on other offers in which they were unable to take part (e.g. parallel workshops). Further, discussions, which began at the event, can be continued online. In this way visitors to the event are able to gain inspiration for their own activities. The mixed format alone means that participants can be addressed multi-sensually at different points of time in the events. An essential characteristic of a marketing event is therefore already fulfilled.

In the following section 4 , the above-described elements of the Blended Conference are now presented in the form of a practical example, which was implemented by the German Rugby Association (DRV) earlier in 2018.

\section{Implementation of the Blended Conference by the DRV}

The DRV is a rugby association within the DOSB. With its 13 regional associations and 124 clubs it is a relatively smaller association in the German sports landscape. The sector for education and training of trainers in a professional association has been managed alone since 2016 by Peter Smutna, the former Austrian national team trainer and has institutional connections with the German Rugby Academy (DRA). This is responsible both for the content and concepts for the teaching courses and also for carrying them out.

In 2017 the DRV applied for an allowance from the Innovation Fund of the DOSB with the project "Introduction of Social Video Learning and Digital Media in the Training of Trainers and Referees" and was granted this as one of 22 project applications. With these financial means the DRV was able to design, develop and carry out a new concept for the training of trainers for an " $\mathrm{A}$ " License. As well as 
developing the concept for a training program, it was also necessary to advertise this accordingly and to make sure of broad acceptance of this new approach in the association. Peter Smutna's team decided on the organization of the "First German Rugby Forum" as a Blended Conference in order to achieve exactly this effectiveness in marketing.

First online phase $\left(15^{\text {th }}\right.$ Jan. $-27^{\text {th }}$ Jan. 2018): Start of a Blended Conference begins between two and four weeks prior to the personal meeting at the location and this was an online conference. Online means that the participants who have registered for the event are invited to an online environment via e-mail. A total of 100 participants were invited to the Campus (Illustration 2).

\section{Illustration 2. Campus}

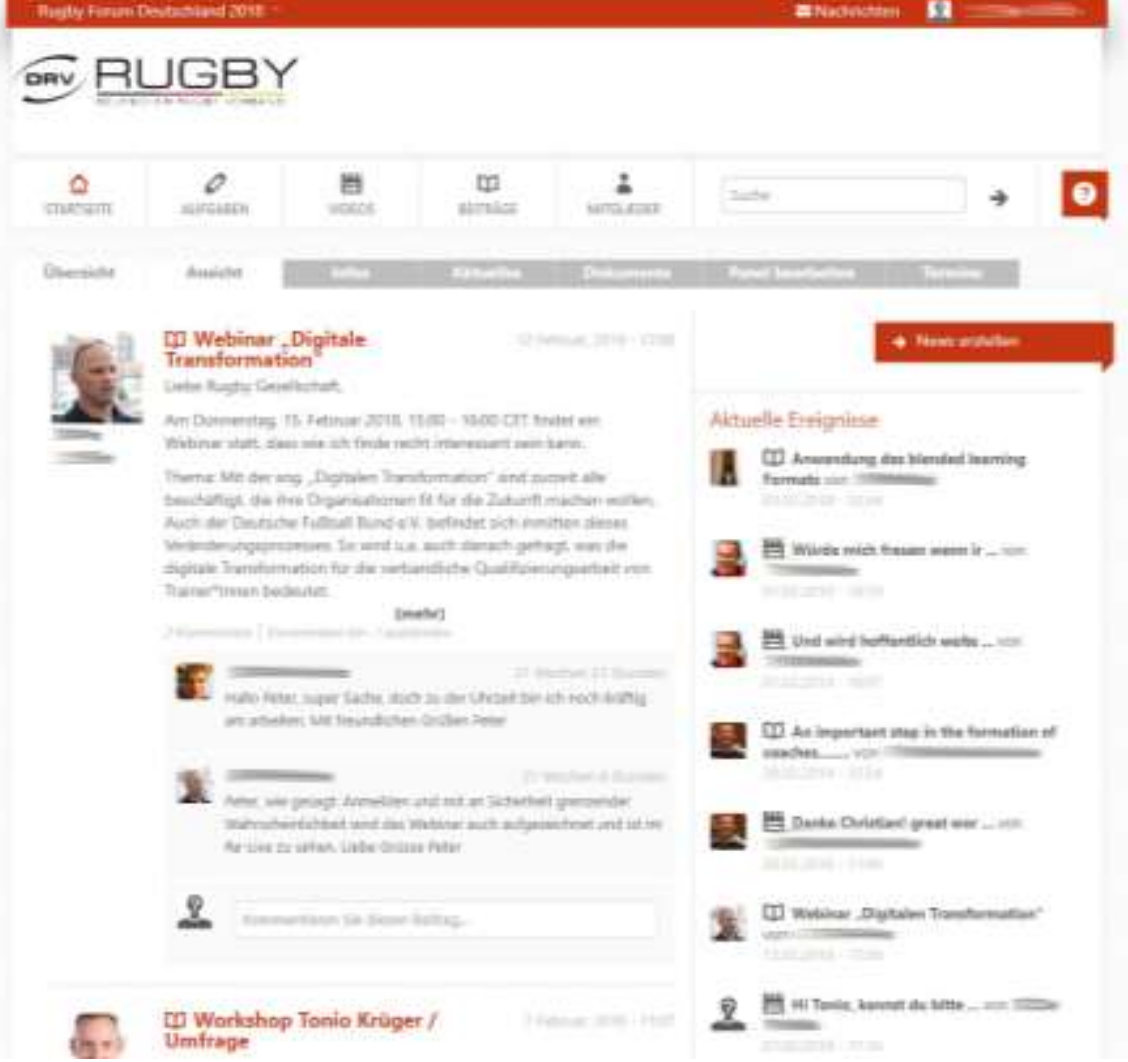

Source: Ghostthinker GmbH 2018.

This environment functions as the virtual event location. Participants enter here regardless of time or place. This introductory online phase has two specific aims: a) to introduce the participants to the subject of the event and b) to capture the needs and questions in this respect of those taking part. The participants are asked to submit their personal profile to the environment, which results in a practical side effect, namely, that the participants are already able to get to know a little about one another. In general the use of an online environment is recommended when this is designed for exchange and interaction.

For the implementation of its further training offers, the DRV uses the online learning environment edubreak ${ }^{\circledR}$. For this reason it therefore also made sense to 
use this this too, for the Blended Conference. edubreak ${ }^{\circledR}$ is characterized primarily by special technical and didactic possibilities under the framework of social interaction and communication in videos (Illustration 3). Each person taking part can integrate video commentaries in a video with text and drawings and can enter an asynchronous discussion with a third party, and known as "Social Video Learning" (Vohle and Reinmann 2014).

Illustration 3. Screenshot Video Player Social Video Learning

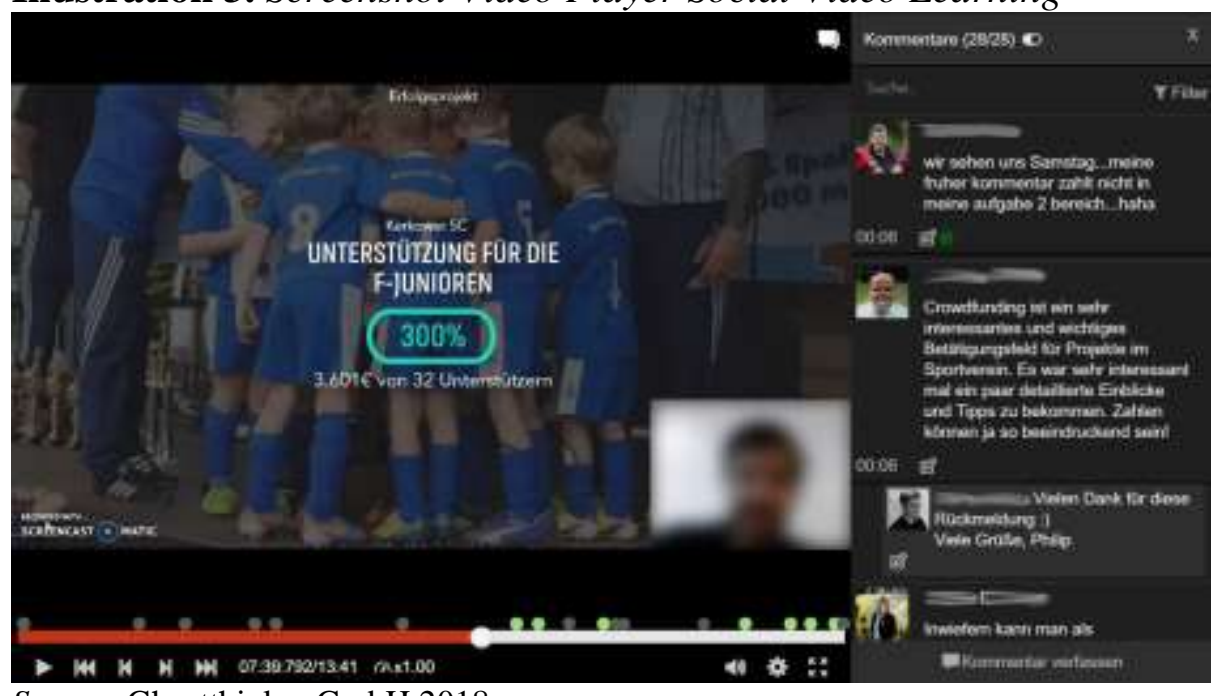

Source: Ghostthinker GmbH 2018.

All the people who were invited to the first German Rugby Forum (RF) were informed already in their invitation about the special format of the event. With the confirmation of registration they were then informed of the exact date (ca. two weeks prior to the personal meeting) when the e-mails with the invitations were sent out in the online environment. In order to make the event as attractive as possible for the desired target group, mostly holders of a B or A License, the program was designed such that the visitors could offset with credits for their license renewal. The introductory online phase of the event has an asynchronous setting. This means that following the invitation, the participants can enter the online environment regardless of time and place and can familiarize themselves with the inputs to be found there. In particular, this format enables a high level of flexibility in respect of the initially described time restraints with which nowadays we are confronted.

As mentioned above, in this first part of the event the aim is to introduce the participants to the theme of the event more intensively than is the case in classic formats. When working at the Blended Conference with the online learning environment edubreak $^{\circledR \text {, }}$ to a great extent the solution is by means of the use of videos. This is how it was done at DRV. The instructors of the keynote lectures introduced their subjects in a short video. In addition they also presented their points of focus. In the form of a small assignment the participants were then required to contribute their specific questions or thoughts relating to their own experiences as written comments to the videos. This feedback to the instructors is 
a central element of the Blended Conference. In this way prior subjective knowledge and opinions of the participants are then visible to the instructor for the first time. The target group thus becomes more tangible and the contents of the presentations can be more clearly adapted to their specific needs. Right from the start the participants are made to understand the possible active involvement on their part: "You are part of this event and you have the possibility of taking part in the form of contents and the way it develops". This possibility of interactive participation in an event with the objective of direct contact with the organization or similar and being "a part of the whole" mostly has an influence on the attitude of the visitor and in the end leads to loyalty towards the brand, the idea or the organization (Zanger 2007). With this step therefore, a further quality feature of a marketing event is fulfilled, namely, the event is held with target group orientation and increased involvement of the recipients. When feedback has been received it is important that the instructors have access to this input and thus work it into their presentations accordingly. In respect of the content of the presentations, this of course demands certain flexibility on the part of the instructors but at the same time can also provide them with valuable knowledge.

In addition to the keynote lectures, the RF also offered two sessions each with three parallel workshops. These were also presented in a video in the introductory phase. Especially when offers run parallel it is very valuable for participants if they are able to deal with the themes more intensively in advance. Of course here too, it was possible for the participants to ask specific questions or contribute thoughts directly on video. From the viewpoint of the organizers and those holding the workshops, this is a very efficient way of working. As well as information transfer, the participants can also be asked to register right away for one of the workshops as this for example, makes room planning much easier. Through feedback the workshop leaders can also be better prepared for their students. Further, the workshops can be arranged on a much more practical basis if the introduction to the theoretical background has already taken place online.

From a marketing viewpoint, this way of working means especially that the program is oriented ideally to the needs of those taking part and the positive feelings incurred in this way are passed on to third parties.

Physical Event (27 ${ }^{\text {th }}$ Jan. 2018): On 08.04.2018 all the participants of the first German Rugby Forum met at the Hanover location of the State Sports Federation of Lower Saxony. This meeting, however, did not have the same character as a classic congress or conference. At a Blended Conference those taking part all know one another beforehand from their online profiles in the online environment. The exchange of a profile photo and short description of activities carried out at which club or organization is helpful not only during the online time but also means that in the face-to-face event the participants quickly start up conversations together, even though they did not know each other before. The quick connection with the group usually leads to a relaxed atmosphere but at the same time motivational and with positive effects for taking in further information (GrederSpecht 2009).

Through the information transfer during the introductory online phase the participants are well prepared when they come to the presence meeting and this 
state of preparation leads to greater activation in respect of the day's program. Moreover, the participants are interested to find out how their own feedback on the lectures and workshops has been received and integrated by the instructors. The moment in which those taking part recognize the added value of the introductory online phase shows the way of everything that can be implemented in future in this organization in Blended Learning format. It begins when in their lectures and workshops the instructors incorporate the input received from the students during the online phase in the form of video commentaries. The message "You can codesign, you play an important role and we value your expertise" is totally effective at this point and leads to even greater activation amongst the recipients. Moreover, the common state of knowledge generated through the preparatory information in the group enables a substantially more in-depth analysis of the subject matter. This is equally valuable to both instructors and participants. For the participants this means that the exchange has already begun at a significantly higher level although the composition of the group taking part is possibly rather diverse. This was also the case at RF. The program was therefore accordingly also wide-ranging in themes.

Each of the six keynote lectures was recorded on video and subsequently entered online. This type of documentation has numerous benefits not only for the participants and instructors but also for those people who despite their registration were not able to take part. Instructors benefit from the possibilities for reflecting on their own performance, which also "pays into" their personal quality development. For participants the recording is a valuable and long-lasting source of information and anyone who was unfortunately not able to take part in person in this way nevertheless has the opportunity to assimilate the input. Generally the documentation of individual program points on video is a central feature of the Blended Conference format. Only continuous documentation and critical reflection of the contents from various perspectives lead to the further development of the themes. In addition, this also leads little by little to the establishment of a new form of communication and culture of quality.

During the face-to-face meeting of the Blended Conference there is also a focus on interaction amongst the learners and the experts. Information, which in the form of interactive elements comes alive to the individual or in the group, results in long-lasting learning success (Lasslop et al. 2007). For this reason it is recommended that the program is designed in such a way that the theory units alternate with the practice elements. These practice elements could be implemented for example, as interactive workshops or in the form of exercises or games, which make the theme or themes of the event a physical experience. The more creative the units, the longer they remain anchored in the memory of the participants. There is also definitely no harm in practice work with humor. The better the participants feel at the event the more positive will be the judgment about the whole of the event. Moreover, "being active together" as a rule triggers a feeling of "it was worth it". The day of the personal meeting should offer the participants exactly that which is not possible during the online times: laughing together, physical activity, experience of the community in real terms. The quantity and quality of processing the messages provided at the event increase in 
direct proportion to the quantity and quality of the emotional experience" (Lasslop et al. 2007). Affective constructs include emotions and moods. Drengner (2007) writes that positive emotions experienced during an event have positive effects on the overall judgment of the event.

The organizers also acknowledge the online preparation positively. The more informed the participants are, the easier it is to maintain the planned schedule. Particular for workshops there is a danger that valuable time is lost on site, for example, through a lack or orientation on the part of the attendees. With prior information about the subject matter and the questions or comments beforehand the practical sessions at the Blended Conference of the DRV were successfully planned. In the DRV program there were two workshop blocks, each with three parallel themes. Like the keynote lectures, the workshops are also recorded on video. The above-mentioned advantages resulting from documentation in this form also apply here. When the program has parallel teaching units then the decision in favor of a workshop does not mean that other elements are neglected. Thanks to the recording, the participants also have asynchronous access and can view at a different time.

Second Online Phase ( $28^{\text {th }}$ Jan. $-28^{\text {th }}$ Feb. 2018): The third and wrap-up phase of a Blended Conference again takes place entirely in the online environment. This should also comprise at least two weeks but can last up to four weeks, as shown in this example. As a rule the organizers begin to put the recordings of lectures and workshops online either during or immediately after the personal meeting. Now the energy and suspense of the presence day must be transferred to the online phase. Here the challenge should be met especially by the central figures of the event. It is in their hands by means of a motivational presentation for example, to revive discussions, which have begun at the location, or to instigate inspirational reflection through the recordings. This is a further central difference to classic event formats. The Blended Conference offers the possibility to continue talking together online and to bring lines of thought to a conclusion.

An extremely effective instrument in this phase is the assignment of small work tasks to the participants to be carried out analogous to the introductory online phase. These are helpful in revising everything learned and experienced and enables reflection from different perspectives. In the third phase the focus is also on the dimension "Inspiration". Through the recordings, everything learned and experienced by the participants themselves stays longer in one owns memory (Bruner 2008, Barett 2005). Mental processing can therefore be more intensive and sustainable. In this way the individual has more time to process the subject matter and its importance in respect of one owns context, thus gaining inspiration for his own implementation.

Also from the point of view of organization the wrap-up phase in the online environment especially brings added value in respect of assuring quality and for further development. Questionnaires can be processed online and the recordings of the teaching units (lectures and workshops) evaluated. Of particular value is the asynchronous and therefore delayed time factor between the actual meeting and the filling out of the survey assessment. 
Depending on how good the presenters are in this online phase and to what extent the subjects of the event have motivated the recipients to active thought, in the concluding online phase there can be a very exciting effect, namely, that by means of the video commentaries the lectures and workshops are not only considered individually but further thoughts developed jointly. Moreover, here too, anyone who is unable to attend the personal meeting can nevertheless have a say.

For the step from the presence phase to the online world the organizers of the RF used the instrument "Newsmeldung" in edubreak ${ }^{\circledR}$. In this way they remind again about the wrap-up online phase and point out specifically their own anchors for reflection in the videos, which have been incorporated by the instructors or the workshop supervisors under the framework of self-analysis. Furthermore, the DRV used the third phase of the event in order to call for a transparent feedback process for the individual event elements. Very important amongst other things of course, are also the wishes for the next RF.

At the end of the two weeks, the official end of the event was announced and the online arena was closed for further modifications. Closed in this case does not mean that participants no longer have access to the contents and resources, but only that no new material can be added. This is of great significance in the sense of long-term securement of documentation and a continuous life-long learning process.

With regard to the effect of this phase on a marketing level, what counts is the contribution to long-term influence on the public. To experience how this combination of online and presence feels, where the benefits lie and what other possibilities there are both for the individual but also for the whole group is fundamental to an internal association "advertising campaign" for a new form of educational training.

The example of the RF, which was implemented as a Blended Conference clearly demonstrates the possibilities, contained within the format from a marketing and organizational view. Point five shows an evaluation of the first results of the questionnaire. This is the questionnaire to participants in the third online phase as described above. Through input from the online phase the participants have a similar level of knowledge, such that the event for everyone involved becomes a more intensive experience and richer in content.

\section{Findings/Results}

In terms of method the approach outlined here has an explorative aim, namely to present the new design of an event format under a marketing framework and to collect first experiences in a practical context so that in a follow-up step it can be customized to the requirements in context. For this reason, at the end of the RF we started an online survey amongst the participants to discover how satisfied they were. The following overview contains the respective items and the results. 
Illustration 4. Evaluation Overview

\begin{tabular}{|c|c|}
\hline 1. Overall impression of the Rugby Forum 2018? & $\begin{array}{l}1.35 \% \\
2-50 \% \\
3-10 \% \\
4-5 \% \\
5-0 \%\end{array}$ \\
\hline 2. How did you like the choice of topics? & $\begin{array}{l}1.25 \% \\
2.50 \% \\
3.20 \% \\
4.5 \% \\
5.0 \%\end{array}$ \\
\hline $\begin{array}{l}\text { 3. How did you like the Landessportbund Nieder- } \\
\text { sachsen as the event location? }\end{array}$ & $\begin{array}{l}1.70 \% \\
2.25 \% \\
3.0 \% \\
4.0 \% \\
5.5 \%\end{array}$ \\
\hline 4. How do you rate the catering? & $\begin{array}{l}1-25 \% \\
2-40 \% \\
3-30 \% \\
4-5 \% \\
5-0 \%\end{array}$ \\
\hline 5. How did you like the moderation? & $\begin{array}{l}1.70 \% \\
2.25 \% \\
3.0 \% \\
4.5 \% \\
5.0 \%\end{array}$ \\
\hline 6. What is your opinion towards value for money? & $\begin{array}{l}1.30 \% \\
2.20 \% \\
3.40 \% \\
4-10 \% \\
5.0 \%\end{array}$ \\
\hline 7. Especially interesting for me has been: & $\begin{array}{l}\text { Event marketing - } 20 \% \\
\text { Offspring - } 35 \% \\
\text { Coaching - } 20 \% \\
\text { Digital learning - } 25 \%\end{array}$ \\
\hline $\begin{array}{l}\text { 8. In your opinion - when should the Rugby Forum } \\
\text { take place? }\end{array}$ & $\begin{array}{l}\text { Winter break - } 95 \% \\
\text { Summer break - } 5 \% \\
\text { Other Date - } 0 \%\end{array}$ \\
\hline 9. How long should the event be? & $\begin{array}{l}\text { One day (Saturday) }-80 \% \\
\text { One day (Sunday) }-0 \% \\
\text { One and a half day (Saturday }+ \text { Sunday) }-20 \%\end{array}$ \\
\hline 10. Additional opinions and suggestions? & $\begin{array}{l}\text { Answers towards the topic "Pricing" - } 18 \% \\
\text { Answers towards the topic "Practice" - } 30 \% \\
\text { Answers towards the topic "Agenda" - } 17 \% \\
\text { Answers towards the topic "Organization" - } 35 \%\end{array}$ \\
\hline 11. Further thoughts? & $\begin{array}{l}\text { - "A phantastic event however the costs were quite } \\
\text { high for just one day." } \\
\text { "There should me more cake": } 4 x \\
\text { "More interaction within the workshops and the } \\
\text { possibility to choose more than one." } \\
\text { "The workshops should be double the time to force } \\
\text { interaction between participants." } \\
\text { "Less impulse presentation, more practice as well on } \\
\text { the pitch if possible." }\end{array}$ \\
\hline
\end{tabular}

Source: DRV 2018.

Right from the start (Illustration 4) it is conspicuous that the evaluation of the Rugby Forum is extremely positive. 50\% evaluate the event as grade 2 and $35 \%$ even as grade 1 . This can certainly be deemed as the first very positive result but which, however, should still be regarded with caution. Drengner (2007) and Trommersdorfer (2004) write that in order to get a positive attitude towards an 
event or the object of an event, then first it is necessary that several events are attended. They assume that "in the case of a one-off visit to an event there cannot yet be a long-lasting reaction in the sense of the common understanding of attitude as the result of inner learning, the relatively long-lasting readiness of an individual to react consistently positively or negatively to environmental stimuli or objects" and therefore they talk about an event evaluation.

The questionnaire shows quite clearly that the date selected by the organizers was considered ideal. 95\% of persons asked were in favor that the next RF should again take place in the winter break. Further, the organizers obviously also got the duration of the personal meeting right. For the coming year too, $80 \%$ of the participants would like a one-day event.

The selection of topics also met with a positive evaluation. Even though this was not asked explicitly in the questionnaire, it can be assumed that the broad spectrum of offers led to this evaluation. The heterogeneity of the recipients is also reflected in the selection of topics, entirely in line with the saying "something for everybody".

This assumption is also confirmed by the answers to question 07: "What was particularly interesting for me?" Each of the subjects offered was evaluated at least once as "especially interesting". Overall it can also be ascertained that the keynote lectures and the workshops were both predominantly evaluated positively. If one considers the scope of the one-day program this is significant because this was calculated and the units scheduled in a very tight timeframe. Unfortunately at this point it can only be speculated as to whether the full program was so well received because the attendees were well prepared.

Also in question 07: "What was especially interesting for me?" it is clear that both the learners and the instructors found the use of the accompanying online environment to be valuable. So, for example "the interchange amongst participants outside the frame (online)" was mentioned specifically as being interesting. On the part of the instructors "the possibility as an instructor to advertise my particular theme for the workshop" was claimed to be extremely interesting and contributing to successful execution of work.

Response to the question of what wishes for improvement should be considered for the following year quickly showed quite clearly that the participants place a major focus on practical elements of the event. This makes the significance for the attendees of these interactive elements quite clear. More practical time spent and the use of time spent actively together was one of the core statements of the survey.

It is interesting that very often "the lack of cake and a further coffee break" was criticized. This seemingly insignificant detail however, shows what is important to the attendees and at the same time what they remember, namely, "enough cake". 


\section{Conclusions}

Through the example of the First German Rugby Forum the concept of the new event format Blended Conference could be clearly demonstrated together with how this can be put into practice. From our point of view this new format is of particular interest for the instrument mix of education marketing as at its core is the use of state-of-the-art education technology. The "Blended" format gains in importance in particular in respect of the latest developments in the education sector of organized sports.

Extending the quality of the event arena by means of an introductory and a wrap-up online phase opens up completely new possibilities both for the organization and also and especially for the content-related design of the program and presentation of the messages. The personal involvement of the participants during the first online phase and the subsequent development of the program in orientation to their requirements has a positive effect on the attitude of the participants towards the event. This was also made clear in the evaluation of the RF. In this preliminary phase the active participation of the students increases, intensifying their willingness to participate at the face-to-face meeting and also their willingness to learn.

The evaluation of the RF questionnaire clearly shows the importance of common practical experience for the target group of sport trainers. The format Blended Conference enables the combining of theoretical background knowledge with experience in practice such that respective specific requirements are optimally met. For the next RF the organizers should bear in mind that an even greater focus should be set here. The purpose of the virtual wrap-up phase is the joint review and discussion of the video results from the presence day. We are talking about generating through this continuity a problem-solving experience in the education field both for the individual but at the same time for the community. Once the participants experience this feeling, this can we compared with the socalled "flow experience". A flow, also known as "the zone" is a state of feelings that is used within motivation psychology (Macht 2004, Csikszentmihalyi 1992). The feedback from participants on the DRV event was very positive. Since it was carried out for the first time there are still countless improvements, which were desired especially on the part of the participants. Nevertheless the implementation of the event in Blended Format proved to be the right decision for the organizers, as is shown by this statement by one of the people taking part: "It was an inspirational event with super lectures and good possibilities to exchange views with other rugby enthusiasts. It would be great if such an event could take place again next year!" (Steve Harris, rugby trainer and instructor in Cologne).

In summary it can be said that through this event format, a low-threshold experience of the still relatively new and complex education format "Blended Learning" becomes possible. In the case of a positive experience this leads to longlasting openness and understanding in respect of this new education format and makes the changeover process and the purchase of the appropriate technological systems probable in the education sector. 


\section{Acknowledgments}

Our thanks to Peter Smutna from the DRV, who gave us access to the insights and results of the inquiry after the event. Further to Wiebke Fabinski DOSB who supported us with the newest numbers.

\section{References}

Barett H (2005) Digital Story Telling Research Design. Retrieved from https://bit.ly/2Dmt JiQ.

Berger Peter L, Luckmann T (1969) Die gesellschaftliche Konstruktion der Wirklichkeit. Eine Theorie der Wissenssoziologie[The social construction of reality. A theory of knowledge sociology]. Frankfurt/Main: Fischer Taschenbuch Verlag.

Bernecker M (2007) Bildungsmarketing, $3^{\text {rd }}$ edition, Cologne: Johanna-Verlag 2007.

Braun S (2014) Ehrenamtliches und freiwilliges Engagement im Sportverein. Befunde, Herausforderungen, Handlungsbedarfe [Voluntary and voluntary commitment in the sports club. Findings, challenges, needs for action]. For the 1st Berlin Honorary Office Dialogue of the Berlin Sports and Leisure Sports Association. Retrieved from https://bit.ly/2PH3Gsr.

Bruner J (2008) Oxford Review of Education 34(3) Teacher Education, the University, and the Schools: Papers for Harry Judge, 287-290.

Csikszentmihalyi M (1992) Flow - Das Geheimnis des Glücks [Flow - The secret of happiness]. Klett: Stuttgart.

DOSB (2013) Das habe ich im Sport gelernt! - Die Leistungen des Sports für lebenslanges Lernen [I learned that in sports! - The achievements of sport for lifelong learning]. Retrieved from https://bit.ly/2ztmkd9.

Drengner J (2007) State of the Art der Wirkungs und Erfolgsforschung im Eventmarketing. In Nickel O (ed). Eventmarketing, 135 - 147. Munich: Franz Vahlen.

EU-Kommission der Europäischen Gemeinschaften (2000) Arbeitsdokument der Kommissionsdienststellen, Memorandum über Lebenslanges Lernen [Commission staff working document, Memorandum on Lifelong Learning]. Brüssel, den 30.10.2000 SEK (2000) 1832. Retreived from https://bit.ly/2CcEFMD.

Greder-Specht Ch (2009) Emotionen im Lernprozess. Eine qualitative Studie zur Erkundung der Beziehung zwischen Emotionen und Wirkungseinschätzungen von Teilnehmenden einer Weiterbildung basierend auf einem entwickelten Instrument zur Abbildung emotionaler Lernverfassungen [Emotions in the learning process. A qualitative study exploring the relationship between emotions and impact assessments of participants in continuing education based on a developed tool for mapping emotional learning behaviors]. In Wissen und Lernen in Organizationen (7). Hamburg: Dr. Krovac.

Lasslop I, Burmann Ch, Nitschke A(2007) Erfolgsbeurteilung von Events. In Eventmarketing, by Oliver Nickel, 117 - 134. Munich: Franz Vahlen Verlag.

Netzathleten (2017) Die Basis des Sports ist das Ehrenamt - Interview mit Boris Rump [The basis of the sport is the honorary office - interview with Boris Rump].Retrieved from https://bit.ly/2ANEecF.

Reinmann G (2011) Blended Learning in der Lehrerausbildung: Didaktische Grundlagen am Beispiel der Lehrkompetenzförderung [Blended Learning in Teacher Education: Didactic Basics on the Example of Teaching Competence]. In BAK Quarterly Seminar 4 (2011). Retrieved from https://bit.ly/2yU2WGL. 
Schäfer-Mehdi S (2009) Event-Marketing. Kommunikationsstrategie Konzeption und Umsetzung Dramaturgie und Inszenierung [Event marketing. Communication strategy Conception and realization Dramaturgy and staging]. Berlin: Cornelsen.

Schüller-Zwierlein A, Stang R (2011) Bibliotheken als Supportstrukturen für ein Lebenslanges lernen [Libraries as support structures for a lifelong learning]. In: Rudolf Tioppel und Aiga von Tippelt (Hrsg), Handbuch Erwachsenbildung/ Weiterbildung 5 Auflage, 515-526. VS Verlag: Wiesbaden.

Simonson J, Vogel C, Tesch-Römer C (2014) Freiwilliges Engagement in Deutschland Zusammenfassung zentraler Ergebnisse des Vierten Deutschen Freiwilligensurveys [Voluntary engagement in Germany Summary of key findings of the Fourth German Volunteer Survey]. Retrieved from https://bit.ly/2umyq3E.

Vohle F (2009) Cognitive Tools 2.0 in Trainer Education. International Journal of Sports Science and Coaching 4 (4): 583-595.

Vohle F, Reinmann G (2014) Social video learning and social change in German sports trainer education. International Journal of Excellence in Education 6(2): 1-11.

Zanger C (2013) Events im Zeitalter von Social Media - Ein Überblick. In Zanger C (ed). Events im Zeitalter von Social Media - Stand und Perspektiven der Eventforschung. Springer Gabler: Wiesbaden: 2013.

Zanger C (2007) Eventmarketing als Kommunikationsinstrument - Entwicklungsstand in Wissenschaft und Praxis [Event marketing as a communication tool - state of development in science and practice]. Publisher: Oliver Nickel. Munich: Franz Vahlen.

Zanger C, Sistenich F (1996) Eventmarketing- Bestandsaufnahme, Standortbestimmung und ausgewählte theoretische Ansätze zur Erklärung eines innovativen Kommunikationsinstruments. [Event marketing inventory, positioning and selected theoretical approaches to explain an innovative communication tool]. Marketing ZfP, 4 (1996): 233 - 242. 
